\title{
Using numerical modeling method for design and constructive controlling of excavation wall in Madison Building, Ho Chi Minh city
}

\author{
Ha Viet Nhu 1, ${ }^{*}$, Binh Van Duong 1, Tuan Anh Vo ${ }^{2}$, Kien Tran Pham ${ }^{3}$ \\ ${ }_{1}^{1}$ Faculty of Geosciences and Geoengineering, Hanoi University of Mining and Geology, Vietnam \\ 2 Vietnam Southern Sub-Institute for Building and Technology, Vietnam \\ ${ }^{3}$ Center for Environmental Consultancy and Technique, Vietnam Environment Administration, Ministry of \\ Natural Resources and Environment, Vietnam
}

ARTICLE INFO

Article history:

Received 1 $1^{\text {st }}$ March 2020

Revised $3^{\text {rd }}$ May 2020

Accepted $30^{\text {th }}$ June 2020

Keywords:

Excavation wall, Madison Building,

Numerical model,

Plaxis 2D.

\section{ABSTRACT}

The basement of a high-rise building is the optimal space for technical systems and parking. However, the construction in narrow urban areas usually has many unstable hazards. In this study, a numerical model has been established and calibrated using the finite element method on Plaxis $2 D$ software that allowed well control of the design and construction processes of the Madison Building basement. The model covers all structural elements and complex engineering geology conditions. Displacements of the excavation wall and surrounding ground base subsidence were analyzed corresponding to the constructive phases of three basements. The analysis results of the numerical model were consistent with the actual construction process that is useful for design and constructive controlling of the excavation wall.

\section{Introduction}

Currently, one of the most widely used urban design solutions in Vietnam is high-rise buildings that could provide several residential units. In high-rise buildings, basements are mostly used for parking space and technical systems. Basement design in high-rise buildings has

${ }^{*}$ Corresponding author

E-mail: nhuvietha@humg.edu.vn DOI: 10.46326/JMES.2020.61(3).03 achieved good performance and is suitable for urban construction. However, the construction often gets unstable geotechnical hazards, especially in narrow urban conditions. The basement construction changes the state of stress, deformation of ground base surrounding excavated area, water table, etc. These problems could lead to ground base displacement, surrounding projects damage if there is a lack of suitable solutions. Therefore, displacement prediction of excavation wall and surrounding ground base subsidence become an urgent task in 
the design and construction controlling of highrise buildings.

The solutions to support the excavation walls are often designed with the general requirement to ensure the strength as well as the stability under the effect of lateral pressure and loadings. Excavation wall stability analysis is usually done using analytical methods, which are based on simple pressure distribution diagrams of Terzaghi et al., (1996). Accordingly, the retaining wall - excavation wall is calculated as a continuous beam that placed on the pillars as sports or anchors. However, this method has an inadequate correlation between wall displacement and surrounding ground base subsidence. It also does not quantify the uncertainty of deformation or displacement estimates (Kung et al., 2007).

In recent years, the numerical modeling methods have been strongly developed basing on the strong development of informatics technology and material models. It overcomes the limitations of analytical methods that their research domain must be highly simplified, medium quantitative results, and there are many factors that are not considered when analyzing. One of the most widely used software to modeling complex soil structure interactions such as excavation as Plaxis 2D. This software uses the finite element method (FEM) for modeling. It allows describing the retaining structure by geometric parameters (length, cross-section, inertia moment), material (specific gravity); support bars/anchors interval; soil properties $(\gamma, c, \varphi, k, E)$, geohydrology parameters, and surface loads. It is also integrated with many modern material models (linear elastic, perfect-plasticity, isotropic hardening, time-dependent behavior, etc.). In particular, the software gives simulation results at different stages of excavation construction (Plaxis, 2011). In recent years, plaxis 2D software has been widely used Vietnam (Krasinski, Urban, 2011), (Krasinski, Urban, 2011), Helmut, 2007, Ngo Duc Trung, Vo Phan, 2011, Chau Ngoc An, Le Van Pha, 2007).

In this study, the numerical model of the excavation wall of the Madison Building (Ho Chi Minh City) was established on the Plaxis 2D software environment. Predicting displacements of the excavation wall and surrounding ground base subsidence were analyzed according to constructive stages from this model, using a finite element method. During the construction of the excavation, the numerical model was calibrated basing on the data of inclinometer deformation monitoring. Predicting displacements extracted from these updated numerical models over time that are the basis for design and constructive controlling of the excavation wall.

\section{Material and methods}

The numerical model for design and constructive controlling of the excavation wall of the Madison Building (Ho Chi Minh City) was established basing on designed structures and geological engineering conditions from TYLIN International Viet Nam (2016). The Plaxis 2D software environment for modeling with three modules: (1) input, (2) calculations, (3) output (Figure 1). The "input" module is used to set and assign input data for the "calculation" module, including geometric modeling, load assign, boundary condition setting, and calculation phase setting. The "calculation" module is used to perform calculation processes according to the

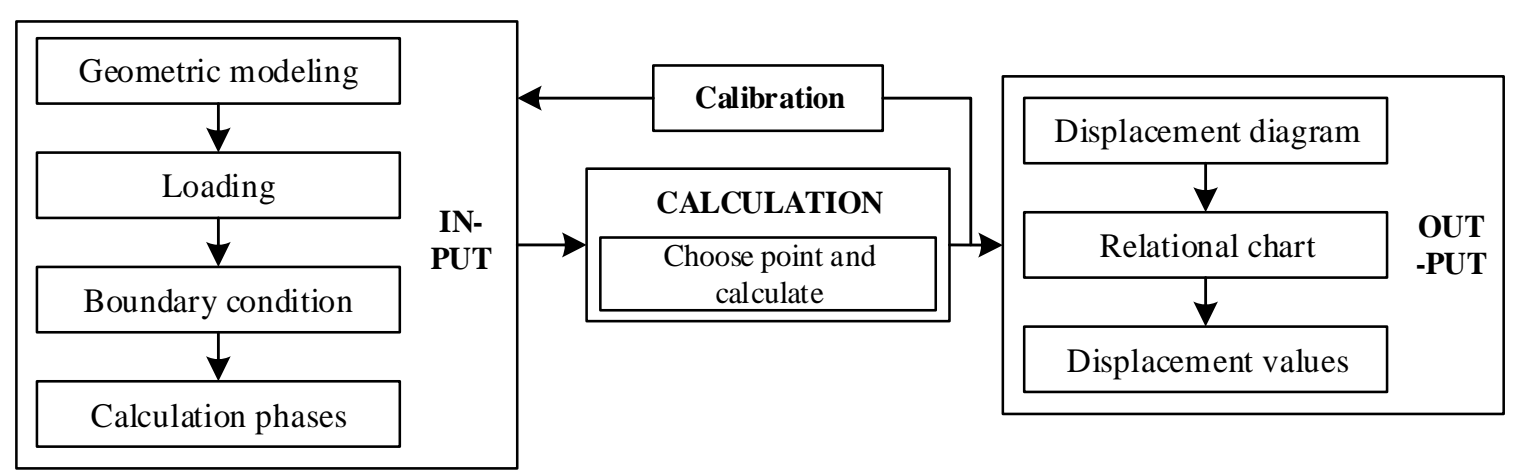

Figure 1. Steps and components of the excavation wall numerical model in the Plaxis 2D. 
actual constructive stages. The "result" module uses the output of the "calculation" module for displaying values, diagrams, graphs of relations between stress and displacement. The numerical was initially assigned a material model as MohrCoulomb (M-C model), then could be updated with others as soft soil model, hard soil model, etc. for calculation. Stress - deformation relationship of these models is a combination of linear and nonlinear behavior. They have good predictability of displacement and failure for geotechnical problems under different conditions.
The geometric model was established according to the designed excavation of $60.29 \mathrm{x}$ $34.37 \mathrm{~m}$, and it's designed structure of the excavation wall of $800 \mathrm{~mm}$ thick by reinforced concrete (Figure 2).

The excavation wall with a depth of $37.0 \mathrm{~m}$ is designed as a retaining wall for the basement (total of 3 basements and $12.9 \mathrm{~m}$ depth) (Figure 3). Excavation walls and posts were modeled as structural elements. In that, the retaining walls were modeled by as "plate" elements, and the post system was modeled as "anchor" elements.

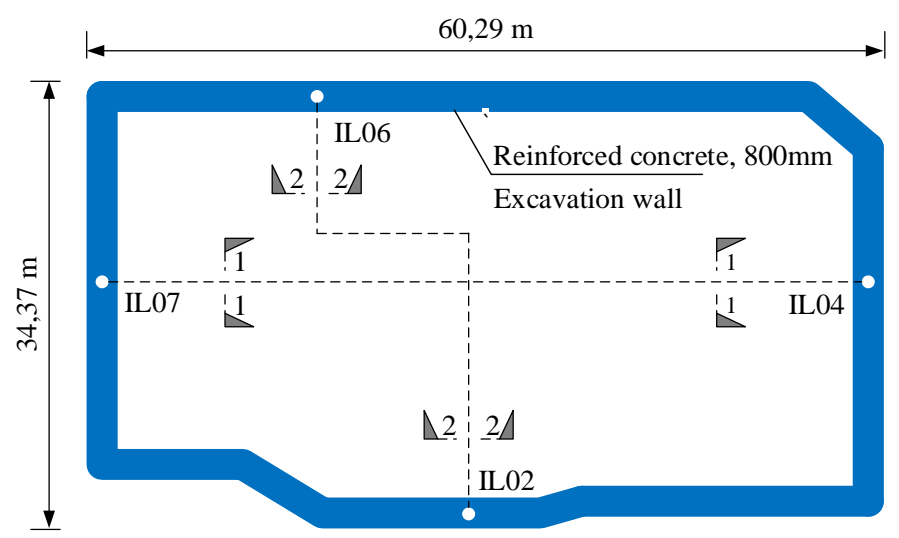

Figure 2. Layout design of excavation wall of the Madison Building (TYLIN International Viet Nam 2016).

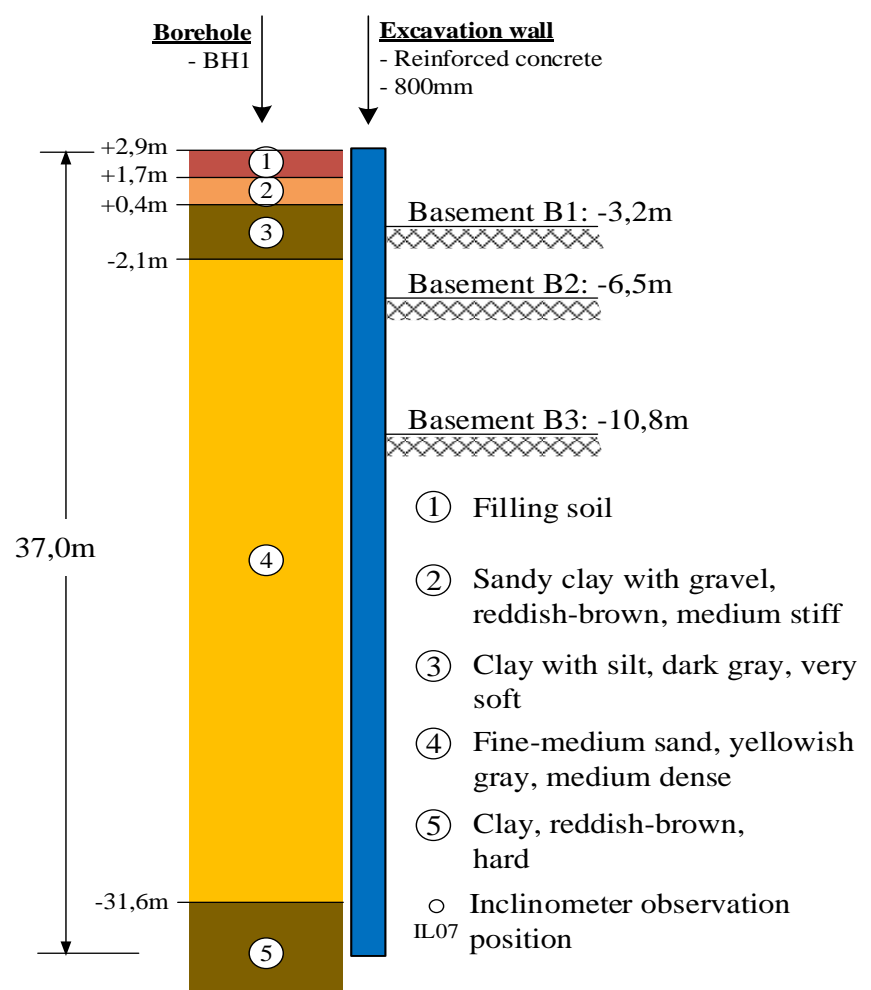

Figure 3. Typical sectional design of excavation wall and engineering geology condition of the Madison Building (TYLIN International Viet Nam 2016). 
Along with the depth of the excavation wall, a total of 5 soil layers (based on the BH1 borehole) were modeled, including: (1) filling soil, $1.2 \mathrm{~m}$ thick; (2) sandy clay with gravel, reddish-brown, medium stiff, $1.3 \mathrm{~m}$ thick; (3) clay with silk, dark gray, very soft, 2.5 m thick; (4) fine-medium sand, yellowish gray, medium dense, $29.5 \mathrm{~m}$ thick; and (5) clay, reddish-brown, hard, unknown thickness (UGEFEM 2015) (Figure 3).

Corresponding to the actual construction phase, the calculation phase of the numerical model was set up in three phases, such as: (1) digging to the bottom of the B1 basement (the bottom elevation $-3.2 \mathrm{~m} \mathrm{),} \mathrm{(2)} \mathrm{digging} \mathrm{to} \mathrm{the}$ bottom of B2 basement (bottom elevation $-6.5 \mathrm{~m}$ ), and (3) digging to the bottom of the B3 basement (bottom elevation -10.8 m) (Figure 3).

The mechanical parameters of the excavation walls were assigned as Table 1, the horizontal posts as Table 2 . The designed load of 20 floors building as $20.0 \mathrm{kN} / \mathrm{m}^{2}$, the road load as 10.0
$\mathrm{kN} / \mathrm{m}^{2}$ and the sidewalk load as $5.0 \mathrm{kN} / \mathrm{m}^{2}$ according to the design documents of the surrounding project (TYLIN International Viet Nam 2016).

The typical properties of soil layers were extracted from the engineering geological survey report (UGEFEM 2015) that were assigned tin to the numerical model of the Madison Building is presented in Table 3.

The characteristics of the groundwater level of the numerical model are determined according to the monitoring data corresponding to the actual constructive phases. At the time of digging to the bottom of the B1 basement, the groundwater level changes from -3.35 m (MW3) to $-4.60 \mathrm{~m}$ (MW4). In contrast, the groundwater level changes from $-3.20 \mathrm{~m}$ (MW3) to $-10.20 \mathrm{~m}$ (MW4) when digging to the bottom of the B2 basement and from $-2.70 \mathrm{~m}$ (MW3) to $-20.40 \mathrm{~m}$ (MW6) when digging to the bottom of the B3 basement, respectively (Table 4).

Table 1. Mechanical parameters of the excavation wall system.

\begin{tabular}{|c|c|c|c|c|c|c|}
\hline Parameter & $\begin{array}{c}\text { Axial stiffness, EA; } \\
{[\mathrm{kN} / \mathrm{m}]}\end{array}$ & $\begin{array}{c}\text { Bending stiffness, EI; } \\
{\left[\mathrm{kNm}{ }^{2} / \mathrm{m}\right]}\end{array}$ & $\begin{array}{l}\text { Weight, w; } \\
{[\mathrm{kN} / \mathrm{m} / \mathrm{m}]}\end{array}$ & $\begin{array}{c}\text { Poisson's } \\
\text { coefficient, v; [-] }]\end{array}$ & $\begin{array}{c}\text { Mp; } \\
{[\mathrm{kNm} / \mathrm{m}]}\end{array}$ & $\begin{array}{c}\mathrm{Np} ; \\
{[\mathrm{kN} / \mathrm{m}]}\end{array}$ \\
\hline DW 800 & $2,160 \mathrm{E}+07$ & $1,152 \mathrm{E}+06$ & 4,8 & 0,20 & $1 \mathrm{E} 15$ & $1 \mathrm{E} 15$ \\
\hline
\end{tabular}

Table 2. Mechanical parameters of horizontal posts.

\begin{tabular}{|c|c|c|c|}
\hline Parameter & Axial stiffness, EA; $[\mathrm{kN}]$ & $\begin{array}{c}\text { Maximum compressive strength, } \\
\text { |Fmax, compl; [kN] }\end{array}$ & Interval, Lspacing; [m] \\
\hline H400 & $3,321 \mathrm{E}+6$ & $1 \mathrm{E}+15$ & 7,5 \\
\hline
\end{tabular}

Table 3. Summary of parameters of soil layers.

\begin{tabular}{|c|c|c|c|c|c|}
\hline Layer & 1 & 2 & 3 & 4 & 5 \\
\hline Type & Undrained & Undrained & Undrained & Undrained & Drained \\
\hline$\gamma^{\text {unsat }}\left(\mathrm{kN} / \mathrm{m}^{3}\right)$ & 19,14 & 19,67 & 20,21 & 19,85 & 20,17 \\
\hline$\gamma^{\text {sat }}\left(\mathrm{kN} / \mathrm{m}^{3}\right)$ & 19,55 & 20 & 20,59 & 20,21 & 20,68 \\
\hline $\mathrm{E}_{50}{ }^{\text {ref }}\left(\mathrm{kN} / \mathrm{m}^{3}\right)$ & 15000 & 28200 & 51000 & 48750 & 100000 \\
\hline $\mathrm{E}_{\text {oed }}{ }^{\text {ref }}\left(\mathrm{kN} / \mathrm{m}^{3}\right)$ & 15000 & 28200 & 51000 & 48750 & 100000 \\
\hline $\mathrm{E}_{\mathrm{ur}}{ }^{r e f}\left(\mathrm{kN} / \mathrm{m}^{3}\right)$ & 75000 & 14100 & 255000 & 243750 & 500000 \\
\hline $\mathrm{m}$ & 0,55 & 0,8 & 0,7 & 0,8 & 0,55 \\
\hline$v$ & 0,2 & 0,2 & 0,2 & 0,2 & 0,2 \\
\hline $\mathrm{c}\left(\mathrm{kN} / \mathrm{m}^{2}\right)$ & 5 & 12,1 & 35,5 & 23,8 & 4,7 \\
\hline$\varphi(\mathrm{o})$ & 25 & 20,8 & 22 & 23,2 & 26,5 \\
\hline$\psi(\mathrm{o})$ & 0 & 0 & 0 & 0 & 0 \\
\hline Rinter & 0,5 & 0,8 & 0,95 & 0,95 & 0,95 \\
\hline
\end{tabular}


During the "calculation", the excavation wall displacement results from the numerical model at the position of inclinometer installation (Figure 2), which were compared with the monitoring results to adjust the input parameters and material model. Along with the process of excavation wall construction, displacements of the excavation wall and surrounding ground base subsidence from the updated numerical models provided the basis for design and constructive controlling.

\section{Results}

The numerical model of the excavation wall of the Madison Building was established that its components, including designed excavation wall and extended ground base structures modeled as a combination of two digital cross-sections perpendicular to excavation sides. After calibrating based on data of inclinometer deformation monitoring, the final material model was assigned as Hardening Soil - HS model for calculation. The model has been calibrated input parameters basing on actual displacement monitoring data for all three construction/ calculation phases (Figure 4).

The analysis results of displacement of the excavation wall when digging to the bottom of the B1 basement from the numerical model showed the maximum value of $11.84 \mathrm{~mm}$ (IL07 position), $13.03 \mathrm{~mm}$ (IL04 position), $11.55 \mathrm{~mm}$ (IL06 position), and $17.03 \mathrm{~mm}$ (IL02 position). The amplitude of displacements is within the allowable limit, according to British Standards Institution (2015). These maximum displacement values are all at the top of the excavation wall and decrease with depth (Figure 5). Accordingly, the analysis results of surrounding ground base subsidence showed the maximum values of -7.16 $\mathrm{mm}$ (IL04 position at the $1-1$ cross-section) and $9.35 \mathrm{~mm}$ (IL02 position at the 2-2 cross-section). These maximum values are all located near the outer edge and decline when they are away from the excavation wall (Figure 6).

Table 4. Summary of groundwater parameters.

\begin{tabular}{|c|c|c|c|c|c|}
\hline \multirow{2}{*}{ Phase } & \multirow{2}{*}{ Period } & \multicolumn{4}{|c|}{ Observation well } \\
\cline { 3 - 6 } & & MW1 (m) & MW3 (m) & MW4 (m) & MW6 (m) \\
\hline Bottom B1 & Ck24 & $-3,50$ & $-3,35$ & $-4,60$ & $-4,40$ \\
\hline Bottom B2 & Ck37 & $-3,45$ & $-3,20$ & $-10,20$ & $-9,60$ \\
\hline Bottom B3 & Ck78 & $-2,85$ & $-2,70$ & $-19,55$ & $-20,40$ \\
\hline
\end{tabular}

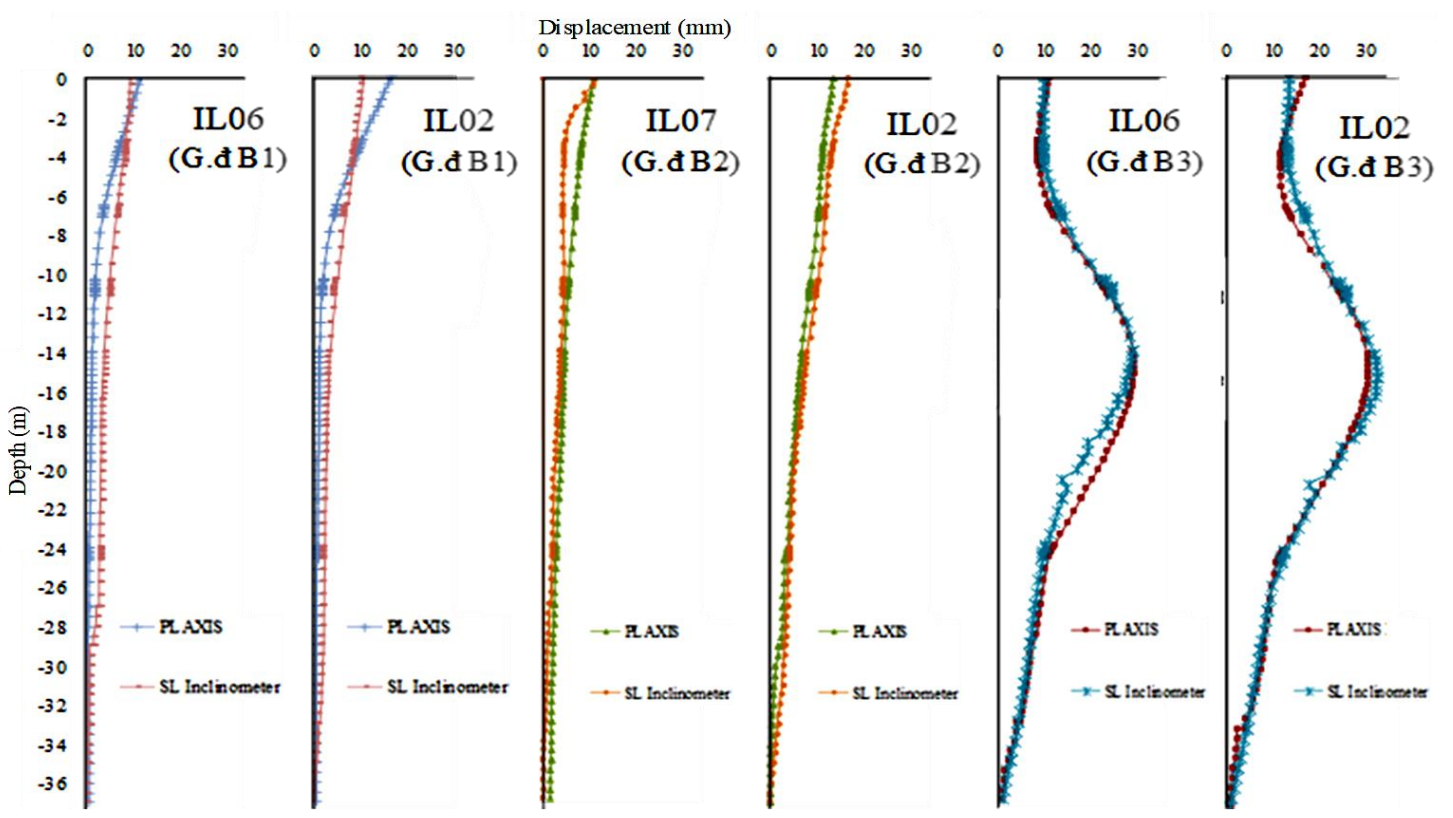

Figure 4. Calibration results of a numerical model based on excavation wall displacement values. 
The analysis results of displacement of the excavation wall when digging to the bottom of the B2 basement from the numerical model showed the maximum value of $11.52 \mathrm{~mm}$ (IL07 position), $13.91 \mathrm{~mm}$ (IL04 position), $11.35 \mathrm{~mm}$ (IL06 position), and $16.82 \mathrm{~mm}$ (IL02 position). The displacement increases at a depth of the B2 basement depth, but the highest values are still at the top of the excavation wall and decline in depth (Figure 7). The amplitude of displacements is within the allowable limit, according to British Standards Institution (2015). Accordingly, the analysis results of the maximum surrounding ground base subsidence reached values of -8.84 $\mathrm{mm}$ (IL04 position at the 1-1 cross-section) and $11.13 \mathrm{~mm}$ (IL02 position at the $2-2$ cross-section). These maximum values are all located near the outer edge and decline when being away from the excavation wall (Figure 8)

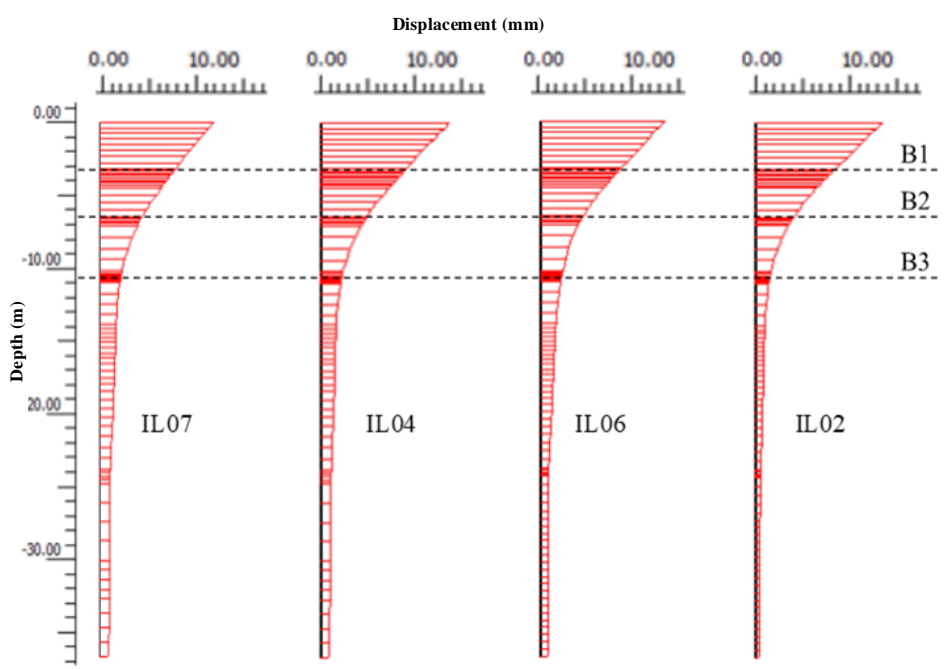

Figure 5. Displacement of the excavation wall of the basement in B1 phase at the 1-1 cross-section (IL07 and ILO4) and the 2-2 cross-section (ILO6 and ILO2).

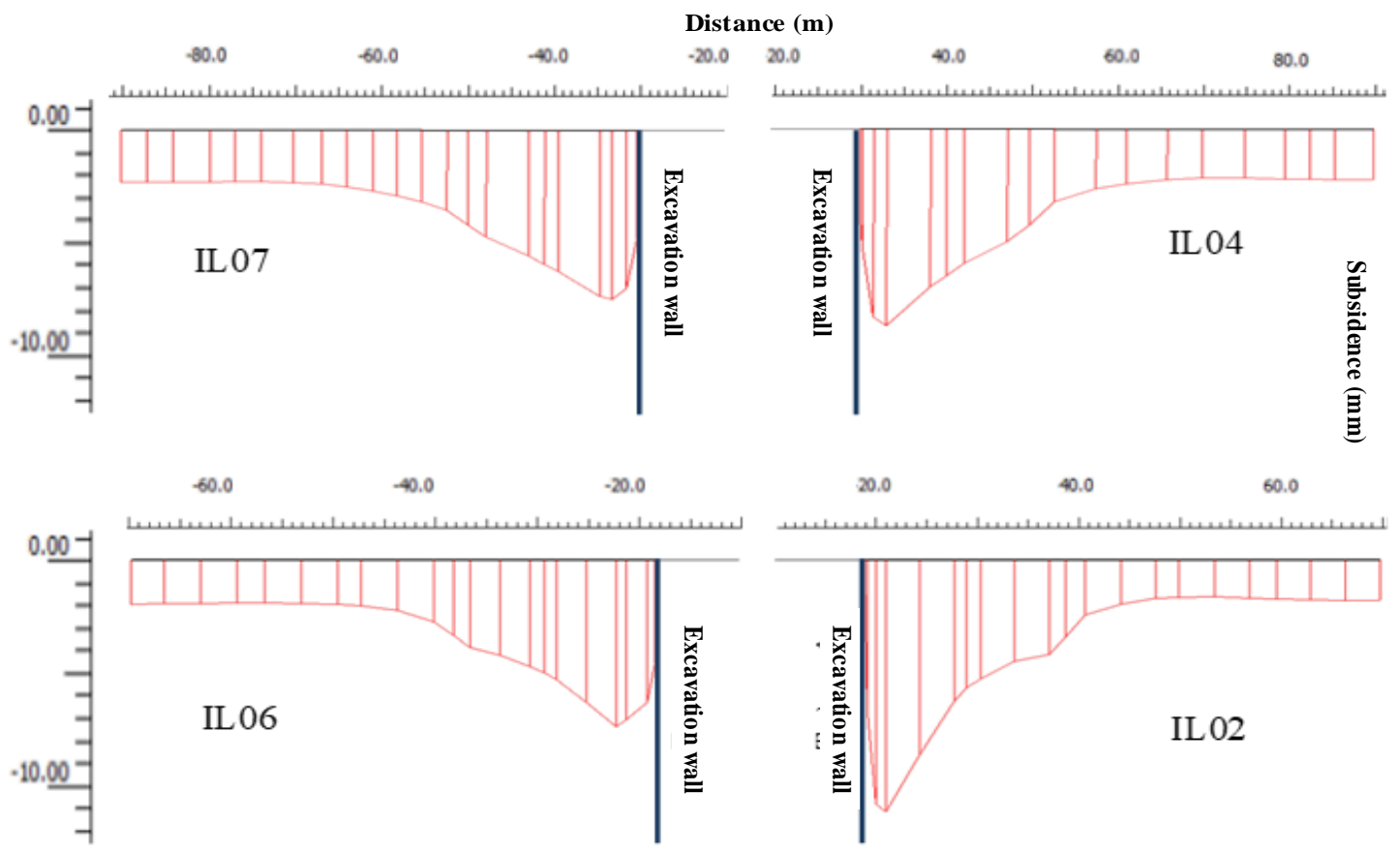

Figure 6. Surrounding ground base subsidence of the excavation wall in B1 phase at the 1-1 cross-section (IL07 and ILO4) and the 2-2 cross-section (ILO6 and ILO2). 


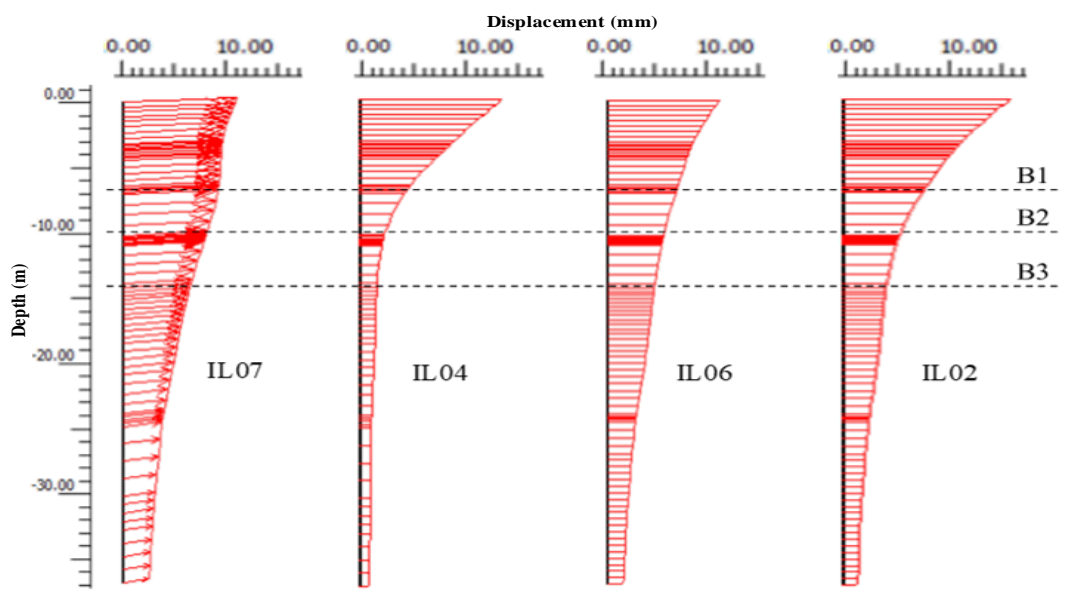

Figure 7. Displacement of the excavation wall in the constructive in $B 2$ phase at the 1-1 cross-section (ILO7 and ILO4) and the 2-2 cross-section (ILO6 and ILO2).

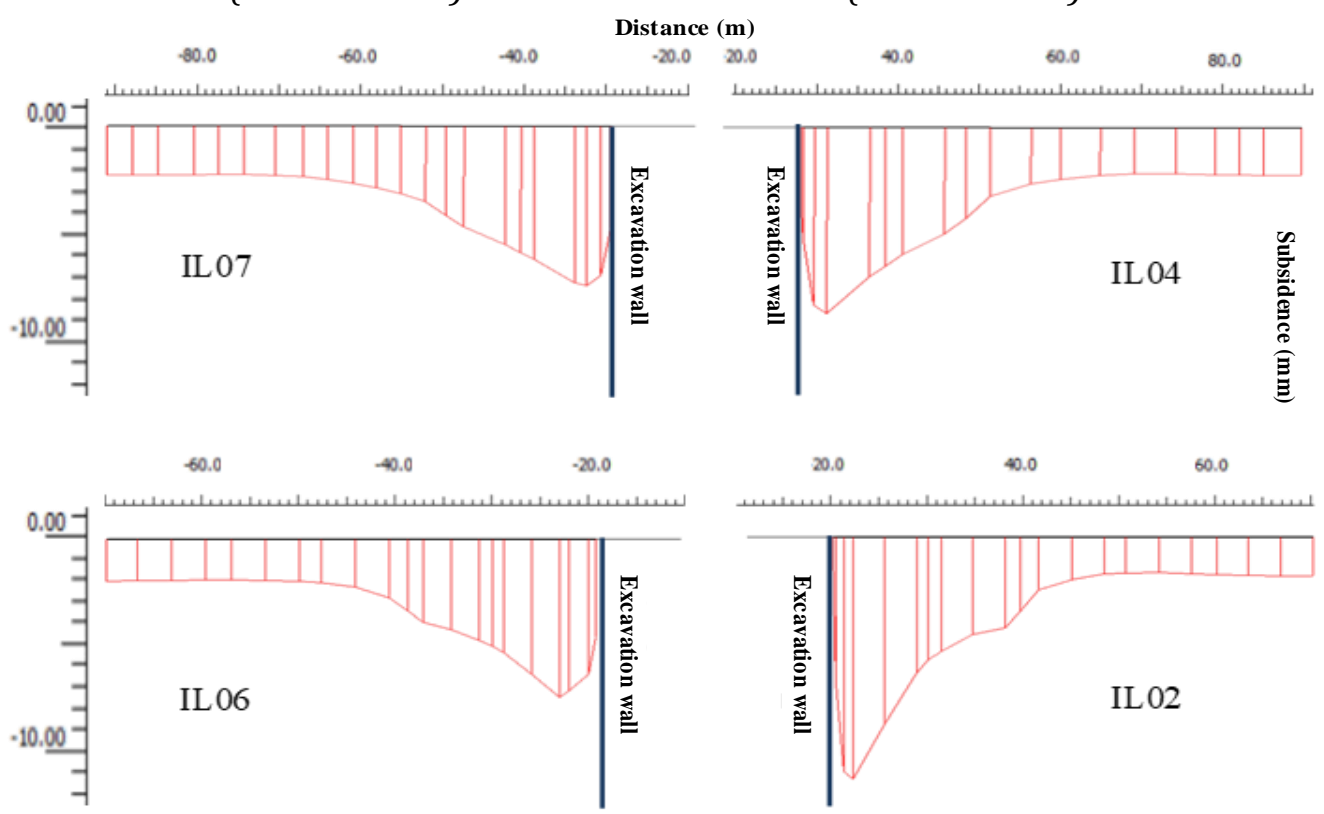

Figure 8. Surrounding ground base subsidence of the excavation wall in B2 phase at the 1-1 cross-section (IL07 and ILO4) and the 2-2 cross-section (ILO6 and ILO2.

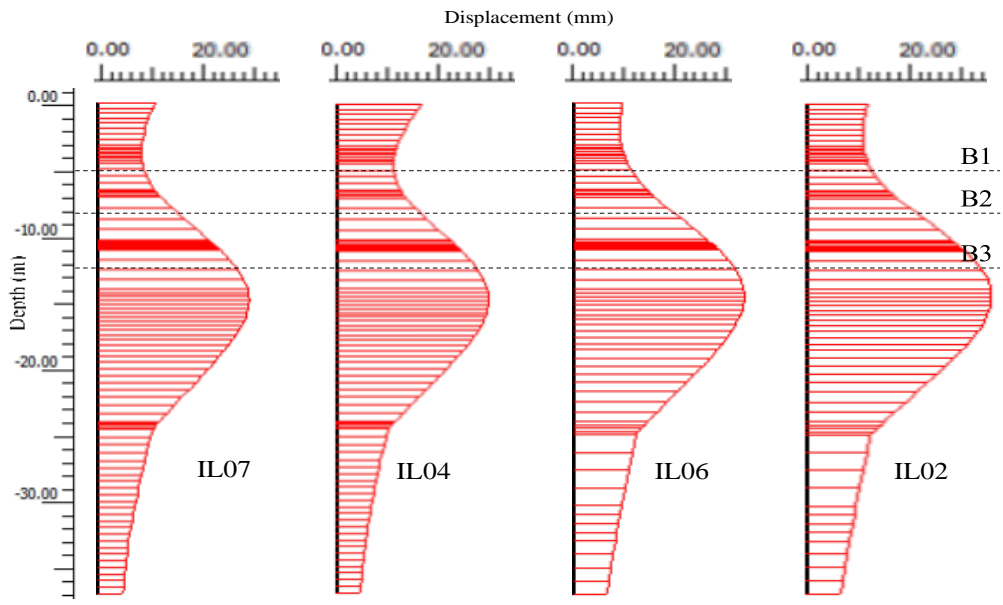

Figure 9. Displacement of the excavation wall of the basement in B3 phase at the 1-1 cross-section (IL07 and ILO4) and the 2-2 cross-section (ILO6 and ILO2). 


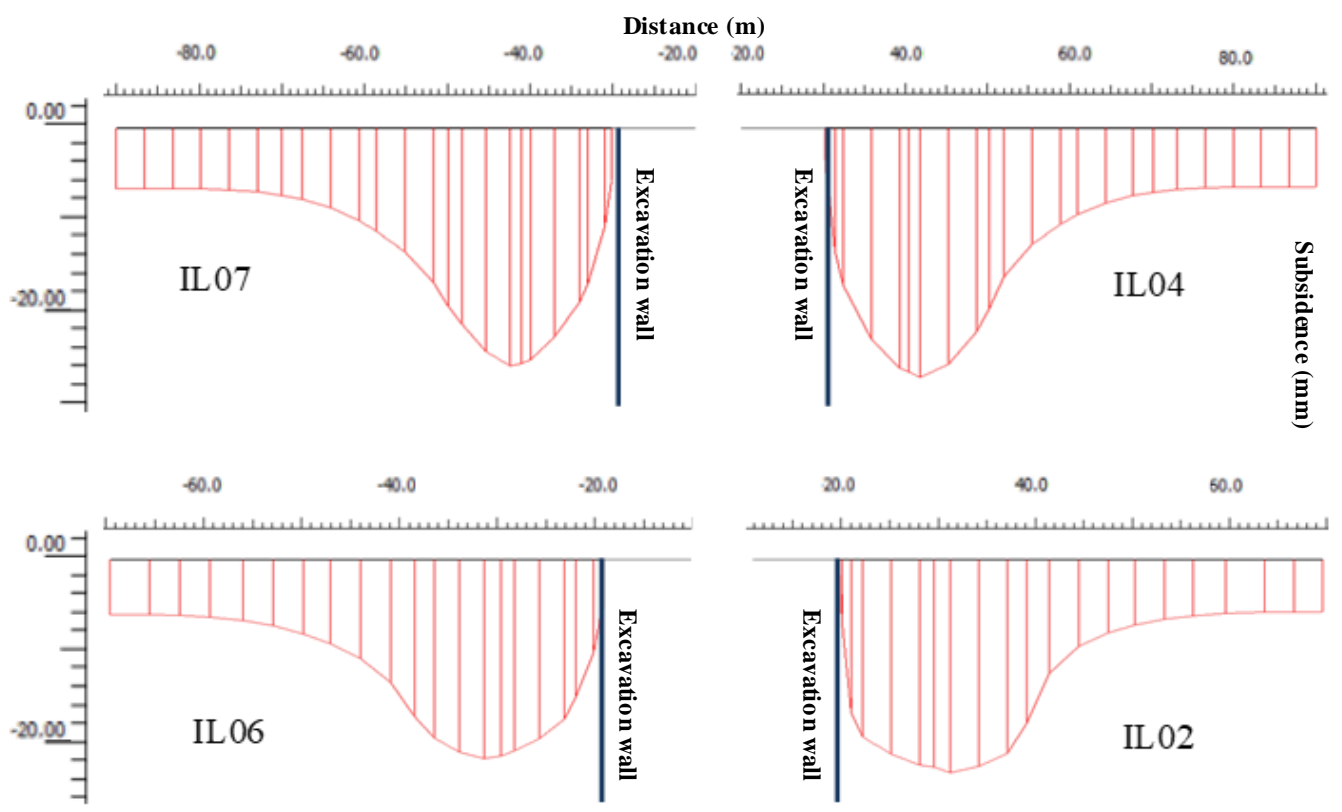

Figure 10. Surrounding ground base subsidence of the excavation wall in B3 phase at the 1-1 cross-section (ILO7 and ILO4) and the 2-2 cross-section (ILO6 and ILO2).

The analysis results of displacement of the excavation wall when digging to the bottom of the B1 basement from the numerical model showed the maximum value of $29.11 \mathrm{~mm}$ (IL07 position), $29.52 \mathrm{~mm}$ (IL04 position), $37.50 \mathrm{~mm}$ (IL06 position), and $37.87 \mathrm{~mm}$ (IL02 position). However, these maximum displacement values are not at the top of the excavation wall but at the bottom of the B3 basement (Figure 9). The amplitude of displacements is within the allowable limit, according to British Standards Institution (2015). Accordingly, the analysis results of surrounding ground base subsidence from it showed the maximum values of $-28.32 \mathrm{~mm}$ (IL04 position at the 1-1 cross-section) and -23.74 $\mathrm{mm}$ (IL02 position at the $2-2$ cross-section). The maximum values are located about $10.0 \mathrm{~m}$ from the outer edge of the excavation wall and decrease when being away from the excavation wall (Figure 10).

\section{Conclusions and discussions}

The numerical model has been established and calibrated using the finite element method on Plaxis 2D software that allowed well control of the design and construction processes of the Madison Building basement. The model covers all structural elements and complex engineering geology conditions.
Displacements of the excavation wall and surrounding ground base subsidence were analyzed corresponding to the constructive phases of three basements. The results showed that the displacement of the excavation wall at all positions increase rapidly when constructing the B1 basement because of delaying in construction of the sport system. All values are within allowable limits, according to British Standards Institution (2015), the maximum displacement values are at the top and decrease in depth of the excavation wall. At the B2 basement constructive phase, the maximum displacement of the excavation wall at all locations (except for IL04) was decreasing due to the sport system which had been completed that makes a balance with the earth pressure. Overall, all maximum displacement values remain at the top of the excavation wall and within the limits of deformation, according to British Standards Institution (2015). When digging to the bottom of the B3 basement, all values of the excavation wall displacement were increasing. The maximum increase is along the long side of the excavation wall (IL02 and IL06 positions) and less along the short side (IL04 and IL07 positions). At this phase, the excavation wall tends to be bending deformation with upper and lower ends fixed and balanced by horizontal pressure by the sports and 
deep ground base. The middle part had the displacement (maximum) with more than double the value of the maximum displacements in phases of the digging to the bottom of the B1 and B2 basements; located in the deeper area which is adjacent to the bottom of the excavation. However, all displacement values were within the allowable limits.

The surrounding ground base subsiding is associated with the displacing of the excavation wall. This subsidence increases according to digging stages, from B1 to B3. At locations that are adjacent to the excavation wall, due to the friction between the soil and the wall, the subsidence values were not maximum. That values were located from $1 \div 3 \mathrm{~m}$ to the excavation wall and gradually decreased with the distance to it. In the excavation stage of the B3 basement, the wall tends to bend deformation, and the displacement rapidly increased to a maximum at the bottom of the excavation. Accordingly, the subsidence also rapidly increased to the previous two phases and reached a maximum at the location about $10 \mathrm{~m}$ from the wall.

In general, the analysis results of the numerical model were consistent with the actual construction process that is useful for design and constructive controlling of the excavation wall. However, because it only modeled as a combination of digital cross-sections perpendicular to excavation sides, it had not been able to model the fullest working conditions. In the future, it could be upgraded in advance with 3D finite element methods.

\section{Acknowledgment}

We would like to express our thanks to Bac Nam 79 Construction Joint Stock Company 79, NQH Architects Company, TYLIN International Vietnam Company, and the Union of Geoscience Foundations - Building Materials for providing data for this study.

\section{References}

British Standards Institution, 2015. BS 8002:2015 Code of practice for earth retaining structures

Chau Ngoc An, Le Van Pha, 2007. Calculation of structure to protect deep foundation pit by the method of considering the simultaneous working between the ground and the structure. Journal of Science and Technology Development 10.

Helmut F. Schweiger, 2007. Modelling issues for numerical analysis of deep excavations. Institute for Soil Mechanics und Foundation Engineering Graz University of Technology, Austria.

Krasinski, A., Urban, M., 2011. The results of analysis of deep excavation walls using two different methods of calculation. Archives of Civil Engineering. 59-72. Versita, Warsaw.

Kung, G., E. Hsiao and C. J. C. G. J. Juang, 2007. Evaluation of a simplified small strain soil model for predicting excavation-induced wall deflection and ground movement.

Ngo Duc Trung, Vo Phan, 2011. Analyzing the influence of ground model on displacement prediction and deformation of deep excavations stabilized by retaining walls. Proceedings of the 12th Scientific and Technological Conference, Faculty of Civil Engineering. Ho Chi Minh City University of Technology.

Plaxis, C. T., (2011). Plaxis 2D v8.2.

Terzaghi, K., Peck, R. B. and Mesri, G., 1996. Soil Mechanics in Engineering Practice, John Wiley \& Sons.

TYLIN International Viet Nam, 2016. Construction drawing of Excavation Wall - Madison Complex Building.

UGEFEM, 2015. Engineering Geological Investigation Report of Madison project at 15 Thi Sach, Ben Nghe district, 1 ward, Ho Chi Minh city. 